\title{
Extensão fenomenológica dos conceitos de saúde e enfermidade em H eidegger
}

\author{
Phenomenological extension \\ of Heidegger's concepts of health and illness
}

Abstract In theZollikon seminars H eidegger gave an extraordinary contribution to the phenomenological study of health and disease. Throughout his life, this was the only chance the philosopher had to deal in depth with these questions. Disease was then determined as an ontological privation of health. Heidegger, however, did not develop an explicit concept of health. The author intends to develop to their full consequences some theses expounded in these seminars taking as reference two determinations then sketched: the essence of human health is identical with Dasein's unfolding essence in its opening to being; any disease is a "limitation of the possibility of living". Key words Heidegger, Analytics of Dasein, Phenomenology of health
Resumo H eidegger deu uma extraordinária contribuição ao estudo fenomenológico da saúdee da enfermidade nos seminários de Zollikon, a única oportunidade, ao longo de sua vida, em queo filósofo pôde tratar com profundidade dessas questões. Aí a enfermidadefoi ontologicamente determinada como sendo uma privação da saúde. Contudo, Heidegger não desenvolveu explicitamente o conceito de saúde. 0 autor busca extrair consequências fenomenológicas das teses expostas nesses seminários a partir de duas determinações aí esboçadas: a essência da saúde humana é a própria essência extática do Dasein em sua abertura ao ser; toda enfermidadeéuma "Iimi tação da possibilidade de viver".

Palavras-chave Heidegger, Analítica do Dasein, Fenomenologia da saúde
1 Instituto de Pesquisa Econômica Aplicada. SBS, Quadra 1, Ed. BNDES, sala 1.420 , Asa N orte. 70776-900 Brasília DF. roberto.nogueira@ipea.gov.br 


\section{A enfermidade como privação}

Numa de suas exposições nos seminários de ZoIlikon, H eidegger ${ }^{1,2}$ afirma quea enfermidade deve ser entendida mediante o conceito de privação, transmitido pela tradição metafísica desde Platão eAristóteles. A privação (steresis, em grego) constitui-senuma negação estabelecida através deuma afirmação implícita de al go que falta. No caso da enfermidade, é sempre mantida uma relação de pertinência essencial à saúde. A enfermidade não é a ausência da saúde, mas é um modo de existir em que a saúde faz falta. A pessoa enferma tem necessidade de saúde, ou seja, carece de saúde: $\mathrm{A}$ pessoa enferma énão-sadia. 0 estar-saudável, o es tar-bem, o encontrar-se bem não está simplesmente ausente, mas está perturbado. A enfermidadenão éa pura negação do estado psicossomático desaúde. A enfermidade é uma privação. Toda privação implica a pertinência essencial de algo ao que lhe faz falta, do que tem necessidade (devido a algumas incorreções da tradução brasileira dos Seminários de Zollikon, para citações desta obra baseiome aqui na versão americana).

N esse sentido, a privação é um fenômeno ontológico que jamais pode ser compreendido com base nas categorias da lógica formal. H eidegger fornece alguns exemplos extraídos do mundo físico: a sombra é a privação de luz; o frio é a privação de calor; o repouso é a privação do movimento. Evidentemente, esses exemplostêm pouca utilidade para uma análise ontológica da saúde humana. A razão se radica num dos pressupostos da analítica existencial do D asein: esteenteespecial que nós mesmos somos não é passível de interpretação através de um ente simplesmente dado. O Dasein não se entende a si mesmo nem pode ser analisado como se fosse a propriedade de um ente dado na efetividade (Wirklichkeit), mas somente pela possibilidade que ele mesmo é a cada momento: Dasein ist je seine M öglichkeit und es "hat" sie nicht nur noch eigenschaftlich als ein Vorhandenes - O Dasein é a cada vez sua possibilidadeejamais a tem somente como uma propriedade dada ${ }^{3}$. Como ente, o Dasein se determina a partir de uma possibilidade, e nessa possibilidade já se compreende a si mesmo de algum modo. H eidegger agrega que este éo sentido formal da constituição do Dasein.

Em conversação com M edard Boss, Heidegger ${ }^{1}$ recomenda que, no plano da interpretação existenciária do Dasein, dever ser empregado o termo potencialidade de ser (Seinkönnen) no lugar de possibilidade (M öglichkeit), para que fique bem demarcado um afastamento em rela- ção à metafísica tradicional. Como se sabe, para a metafísica, um dos modos de ser dos entes é a possibilidade: por exemplo, a madeira (ou a árvore) é a possibilidade de ser mesa. M as, nesses casos, a possibilidade se esgota na medida em queérealizada. Em contraposição, o D asein sempre se mantém como potencialidade de $\operatorname{ser}^{1}$; a tradução brasileira usa poder-ser para traduzir Seinkönnen, quer atue ou não de acordo com tal potencialidade.

0 que se depreende a partir da análise de H eidedgger nos seminários de Zollikon ${ }^{1}$ é que a enfermidade deveser analisada fenomenologicamente como um modo de privação, mas sempre no sentido de privação da potencialidade de ser do Dasein. A enfermidadeéum modo decarecer do Dasein em que ele se compreende como estando numa falta de alternativas de poder-ser. Portanto, ele tem sempre a compreensão préontológica da privação.

Essa interpretação rompe em definitivo com a base cartesiana da medicina moderna em quea enfermidade é entendida a partir de uma res extensa (o corpo físico) e analisada através das modificações de seus constituintes anatômicos, fisiológicos, bioquímicos etc. 0 corpo e suas mudanças patológicas são apenas uma das inúmeras bases para que 0 Dasein se compreenda em privação da saúde, sendo sempre essas bases determinadas pelos modos de ser do Dasein.

$M$ as em nenhum momento dos seminários deZollikon H eidegger ${ }^{1}$ expõeuma determinação rigorosa do que seja a saúde. Isto acaba por comprometer a própria consistência do conjunto das análises fenomenológicas ali realizadas. Com efeito, o que pode significar o conceito de enfermidade como privação da saúde se não é feita uma determinação ontológica adequada do que é a saúde? A relação entre os conceitos de saúde ede enfermidade, de um lado, e o conceito de potencialidade de ser, de outro, não foi devidamente esclarecida.

Essas omissões, contudo, são perfeitamente compreensíveis. 0 filósofo seimpôso encargo de pensar a saúde e e enfermidade num período tardio desua carreira, em encontros esporádicos para os quais não chegou a escrever um texto-base extenso e sistemático como acontecera em inúmeros seminários anteriores, decaráter propriamente acadêmico. Os de Zollikon constituem uma exceção entre seus seminários, já que aconteceram basicamente em virtude do vínculo de amizade que ele mantinha com M edard Boss. $M$ ais decisivo, entretanto, é o fato de que H eidegger tinha um interesse de toda a vida voltado para as 
questões mais gerais da ontologia. Deacordo com suas próprias definições, as questões da saúde pertencem a uma "ontologia regional" e deveriam ser abordadas no âmbito de uma disciplina ainda inédita, a antropologia filosófica do normal e do patológico. Ele esperava, para o futuro, que houvesse o desenvolvimento não só dessa nova disciplina filosófica como também que fossem realizadas sistematizações científicas consentâneas com os fundamentos de sua ontologia4.

A intenção deste artigo éretirar certas consequências analíticas (que denomino de extensões fenomenológicas) a partir de duas determinações esboçadas por H eidegger: (1) a essência da saúde humana é a própria essência extática do Dasein em sua abertura ao ser; (2) toda enfermidade é restritiva da liberdade do Dasein, é uma "limitação da possibilidade de viver".

\section{A essência extática do Dasein}

É preciso recordar sumariamente aquilo que H eidegger manteve como premissa ontológica fundamental a partir do início dos anos 1930: a abertura ao ser que se dá ao Dasein. Aqui, não pretendo medeter nos conceitos muito sutis, mas correlatos, de clareira (Lichtung) e de evento de apropriação (Ereignis). Para os fins de uma de terminação preliminar da saúde, creio que basta ter em vista o conceito de abertura (Offenheit). Cito a partir de um texto pouco conhecido, A essência da verdade, que se originou de um seminário dado na Universidade deFreiburg em 1931 2 e que tem, como um dos seus temas, o mito da caverna de Platão: 0 homem é o ser que entende 0 ser e existe com base nesse entendimento, isto é, entre outras coisas, comporta-se diante dos entes como aquilo que é des-coberto. Existir e Dasein não são usados aqui num sentido vago e desvanecido para significar um acontecer e o estar presente, masnum sentido bem definido eadequadamente fundado. Ex-istir e ex-istente: erguer-se acima de si mesmo em direção ao des-cobrimento, estar entregue aos entes em sua totalidade, e, assim, ao confronto de si próprio com os entes, não fechado em si como as plantas, não restrito ao seu ambiente como os animais, não ocorrendo simplesmente como uma pedra ${ }^{5}$.

A essência (Wesen) do homem tem sempre esse caráter ex-tático, palavra que busca dar a ideia de uma potencialidade de ser além de si mesmo, de projetar-se no espaço e na temporalidade que 0 Dasein abre para si. Não haveria essa abertura se o homem não fosse um ser do- tado de linguagem, com sua habilidade de distinguir o que "é" um ente como tal (uma mesa, um livro), mas não de uma maneira individual, para cada coisa, como se a des-coberta do ente resultasse de uma investigação. A abertura, na compreensão do que os entes "são", está desde sempre dirigida à totalidade do mundo.

0 homem tem mundo como formador de mundo, diz $\mathrm{H}_{\text {eidegger }}{ }^{1} \mathrm{em}$ Conceitos fundamentais da metafísica. H eidegger faz uma revisão detal hada e crítica da literatura científica de sua época nos campos da biologia e da zoologia que ainda nos surpreende por sua atualidade. Leva a cabo um tratamento filosófico de temas específicos e inéditos, tais como órgãos, sistemas orgânicos e conduta animal. N essa obra é desenvolvida com grande profundidade a diferenciação de estatuto ontológico entreo homem, os animais e uma pedra, brevemente referida na citação feita, estabelecendo sinteticamentetrês determinações do estatuto ontológico desses entes ${ }^{6}$ :

(1) a pedra (qualquer ente puramente material) é desprovida de mundo;

(2) o animal é pobre no mundo;

(3) o homem é formador de mundo.

Aqui, "formador demundo" éum conceito que nada tem aver com a conhecida tese de $M$ arx em 0 capital de queo homem éum animal que trabalha com basena antevisão da finalidade de sua atividade. Formar quer dizer trazer os entes do mundo à manifestação, à presença; mas, como precondição, há o trazer-se a si mesmo à manifestação pela resoluta auto-des-coberta do Dasein. Esta auto-descoberta ocorre em referência ao Da do Dasein, no estar-em um mundo, como ser lançado à sua própria responsabilidade. Em meio àmanifestação dos entes, o Dasein, pela resoluta abertura de si mesmo, compreende-secomo sendo sua potencialidade de ser ese faz livre a si mesmo com tal compreensão. Esse resoluto abrir-se para si é o momento da visão (Augenblick).

A abertura para o ser e para si mesmo no Da do Dasein não é só um trunfo, mas um grande perigo, como relembra H eidegger quando menciona a possi bilidade deo Dasein se perder numa condição de privação, que é sempre restritiva de sua liberdade. Isso tudo tem a ver com sua "vulnerabilidade", palavra que Heidegger não usa, mas que se acerca do sentido metafísico da palavra finitude: 0 Dasein está diante de possibilidades que ele não antevê. É sujeito a mudanças que não conhece. M ove-se constantemente numa condição sobre a qual não tem domínio ${ }^{6}$.

0 homem, em sua essência extática, tem 0 mundo em plenitude. Sua potencialidade de ser 
não encontra limitação nem no espaço nem no tempo, os quais, na verdade, são "abertos" pelo próprio Dasein. Ele pode se fazer corporalmente presenteaqui enquanto também está presenteao que está lá, num local distante para onde se dirige. Pode compreender o queéeo quefoi, à luz de sua potencialidade de ser, que está sempre voltada para o que ainda Ihe advirá, ou seja, para o futuro. 0 animal, ao contrário, está limitado às possibilidades dadas em seu próprio ambientee, portanto, aos estímulos que del recebe. É cativo de um círculo de estímulos que se desencadeiam restritamente a partir do ambientee que o levam a suas formas de conduta peculiares. Não há como imaginar queo animal tenha qualquer sentido da temporalidade que é o constituinte existencial axial do Dasein. Em resumo, Heidegger repeteexaustivamente: 0 animal épobreno mundo. Já a pedra é diferente desses outros dois entes, porque simplesmente não tem mundo.

Esse esquema interpretativo que $\mathrm{H}_{\text {eidegger }}{ }^{1}$ adota para comparar o estatuto peculiar do homem em face do animal edo entematerial fundase numa escala qualitativa da possibilidade de abertura. É só no Dasein do homem que a abertura impera, o que implica que está sujeita a fechamento como um fenômeno de privação mais ou menos duradouro. Enquanto 0 animal responde a estímulos, o homem se expressa diante da totalidade dos entes por seu comportamento, queéseu modo particular de responder livremente às demandas do mundo. 0 animal move-se em pobreza no mundo, porque sua forma de ser se expressa numa conduta que não é um modo de ser livre, já que é sempre "tomado" pelos estímulos que vêm do seu ambiente. Ao animal é dada apenas uma abertura bastante limitada, própria deuma catividade. Q uanto à pedra não cabefalar de qualquer tipo de abertura, ela não exibe abertura, está fechada em si mesma. A pedra éo exato oposto do ser do homem, enquanto o animal ainda é comparável ao homem por meio de um modo de abertura que, nestecaso, precisa ser analisado do ponto de vista ontológico como privação. 0 conceito de "abertura em catividade", com o qual Heidegger se refere ao estatuto ontológico do animal, traduz o modo de ser que é peculiar a tal privação. Esta ideia pode parecer antropocêntrica para certas correntes filosóficas, mas é coerente com o pressuposto em cuja base Heidegger construiu sua ontologia: todos os demais entes ganham seu sentido quando comparados com a plena abertura queimpera na essência do Dasein.

Em Conceitos fundamentais da metafísica, ao empreender uma longa discussão de temas da biologia eda zoologia, Heidegger cumpriu parcialmente com certos requisitos preliminares acerca do estudo da vida que ele havia exposto em Ser e tempo ${ }^{7}$. Ele diz aí que a vida é um modo de ser ao qual somente se pode ter acesso por intermédio daquilo que é característico do Dasein e que a investigação da ontologia da vida deve ser conduzida pela via de uma interpretação "privativa" em relação ao modo de ser do Dasein. É assim que se chega a uma determinação do que seria o "mero viver". Contudo, o Dasein em si mesmo jamais pode ser interpretado dessa maneira, como vida, na medida em que vida não é um conceito ontologicamentedeterminado. Esse é um tipo de crítica que ele dirigiu de forma recorrente particularmente a Dilthey e N ietzsche, autores pelos quais nutria admiração. Em relação a Nietzsche, parecia-Ihe de todo inapropriado tentar erigir posições ontológicas com fundamento em material retirado da fisiologia e da biologia, porque cabe à filosofia fornecer fundamentos para a ciência e não ao revés 8 .

A medicina moderna, apelando para os crité rios das ciências naturais, leva a vantagem de poder falar da saúde e da enfermidade como se não dispusesse de nenhum ponto de vista ontológico para defender seus posicionamentos, ou seja, como se constituísse uma pura sistematização de fatos evidentes. René Lericheafirmou que a saúde é la vie dans le silence des organes (a vida no silêncio dos órgãos). A despeito de empregar uma metáfora inventiva, Leriche apenas ratificou o ponto de vista da ontologia cartesiana: há saúde como vida sempreque os órgãos não emitem sinais de mudança patológica, detectáveis e mensuráveis pela medicina. De sua parte, Georges Canguilhem ${ }^{9}$ fala da saúde e da enfermidade como diferentes modos de andar a vida. A enfermidadeé apenas um modo relativamente desvalorizado de andar a vida 9 . Também Canguilhem ${ }^{9}$ se dei xa levar pela ten dência criticada por H eidegger, introduzindo o conceito de vida de forma a priori ea-teórica. Deveser dito que essa compreensão não logra caracterizar o que a saúde humana tem de peculiar, porque certamente 0 animal também tem suas enfermidades como modos diferentes de andar a vida.

Sem sombra de dúvida, a vida é mais tenaz e mais resistente que o Dasein. A vida continua a andar em situações extremas, em que o Dasein já sefechou para si epara o mundo. É o que acontece, por exemplo, nos estados comatosos profundos, que podem ser definidos como "mera vida" e que a medicina denomina de estados vegetativos. Por sua vez, muitos pacientes em situação grave 
do chamado mal deAlzheimer podem apresentar um perfeito silêncio da vida nos seus órgãos, mas já nada ou quase nada compreendem de si e do mundo; são privados, inclusive, da ligação essencial do Dasein com a temporalidade.

A despeito da firme posição defendida pela religião cristã quanto à sacralidade da vida, é preciso dizer queháal go mais precioso quea própria vida. 0 dom mais precioso éo apanágio da abertura ao ser. A saúde do homem radica-se não na vida, nem nosórgãosfísicos, nem sequer na mente, considerada como ente interno racional que guia o homem. A saúde humana, portanto, não é um estado, nem uma condição que se encontra e semedena efetividade dossinais, sintomas ealterações bioquímicas do corpo. A saúde humana é diferente da saúde animal porque ela é a própria essência extática do Dasein. Sendo lançado ao mundo, o Dasein projeta-se sempre em suas potencial idade de ser; mas, como lembra H eidegger em Ser e tempo ${ }^{7}$, o Dasein pode se fechar diante dessas potencialidades e até perdêlas por completo. O Dasein pode ser privado de sua abertura, enquanto a vida e o sistema de órgãos do corpo físico continuam em sua marcha tenaz.

Toda enfer midade é restritiva da liberdade humana

É ao tratar da esquizofrenia que Heidegger deixa claro como a privação da saúde deve ser sempre referida a uma potencialidade de ser do Dasein. A esquizofrenia não éuma enfermidadequalquer: é uma privação da essência extática do homem, ou seja, da abertura do Dasein para o ser, o seu estaraberto-para (offenstehen für). 0 Dasein estáaberto para tudo o que vem à presença, ou seja, para a totalidade dos entes do mundo e para sua própria presença. A esquizofrenia se apresenta como uma privação desse modo essencial de ser; aqui a abertura aparece modificada para uma "falta de contato"1. 0 esquizofrênico comporta-se em seu ser-no-mundo como alguém privado de abertura; por outras palavras, alguém que se encontra fechado. Contudo, no comportamento do esquizofrênico, a abertura não desaparece, mas se mostra em privação. M esmo sofrendo de uma privação, o esquizofrênico "é" ainda sua potencialidade de ser aberto para o mundo e precisa dessa abertura.

Para compreender a esquizofrenia ou qualquer outra enfermidade, não devemosir em busca de suas "causas" na infância ou em qualquer outro tempo e lugar. 0 comportamento do Dasein responde aos motivos que se Ihe apresentam na cotidianidade e não é o resultado de um operar de fatores causais. 0 motivo é uma resposta livremente dada, um "mover-se diante de", que se dá com base na compreensão que o Dasein tem do mundo e de si mesmo.

Tal pressuposto rompe outro elo que a medicina mantém usualmente com a ontologia cartesiana, o causalismo, que foi transposto a partir das ciências naturais. O Dasein élivrejustamente por ser sempresua potencialidade de ser, porque habita a "clareira do ser"; está aberto em sua essência à compreensão dos entes do mundo em sua totalidade e à compreensão de si mesmo: $\mathrm{A}$ liberdade é a condição da manifestação dos entes, do entendimento do ser. A causalidade, contudo, é apenas uma determinação ontológica entreoutras. 0 problema da causalidade está fundado na liberdade e não vice versa ${ }^{10}$.

M esmo numa condição privativa, como a da esquizofrenia ou outra qualquer, ainda vigora esse existencial transcendente que é a liberdade humana, apesar de a enfermidade a limitar em sua amplitude. Em definitivo, o homem não é natureza, submetido a uma cadeia de causas. Tampouco o corpo humano pode se visto como natureza: 0 corpo humano não é pura natureza nem no seu modo imediatamentedado nem em seu modo deser. Está suspenso como sefosseuma via de passagem entre um e outro, entre seu pico e seu abismo, como um lugar aberto de morada para ambos, mas nunca está fechado para si mesmo, nunca está na maneira da pura natureza, à qual completamente falta um eu. 0 corpo pertence ao D asein do homem. (...) A corporeidadedo homem, contudo, não énatureza, nem mesmo quando atormenta o homem, deixando- o sem poder ou sem seu fundamento ${ }^{5}$.

Assevera H eidegger que a essencial abertura humana para o ser contempla várias possibilidades de privação, que são também possibilidades de fechamento. Por exemplo, quando estamos absortos de "corpo e alma" na execução de uma tarefa, há um fechamento do nosso Dasein e deixamos de perceber muito do que acontece no nosso ambientefísico eprestamos pouca atenção às outras pessoas ao redor ${ }^{1}$. Outra possibilidade de modificação ôntica da abertura é a que se dá como "falta de contato", condição peculiar à esquizofrenia. A privação que se constata na esquizofrenia é um fechamento do Dasein com características bem especiais. Pode-se dizer que revela um fechamento da abertura quenão éocasional ou temporário, mas que se mantém como tal e perdura. Desta maneira, H eidegger distin- 
gue uma possibilidade de fechamento queé própria do estar saudável (quando alguém fica absorto numa tarefa) e uma possibilidade de fe chamento que é própria do estar-enfermo (a esquizofrenia).

Ora, a abertura é também fonte de perigo, como acentua Heidegger, porque a essência do homem é imperfeita: 0 homem é essencialmente necessitado deajuda, por estar sempreem perigo de se perder, de não conseguir lidar consigo. Este perigo está relacionado com a liberdade do homem. Toda a questão do ser-doente está ligada à imperfeição desua essência ex-tática. Cada doença éuma perda deliberdade, uma limitação da possibilidade de viver ${ }^{1}$.

Assim, como fenômeno ontológico, a essência da saúde se identifica com a própria essência extática do Dasein, sendo o fundamento de todas as potencialidades "saudáveis" do Dasein no mundo, em sentido ôntico-existenciário. No caso da esquizofrenia, do mal deAlzheimer graveetc., o homem revela uma carência profunda e duradoura de sua potencialidade de ser, uma grande restrição em sua liberdade de escolha e orientação na cotidianidade que o torna necessitado de ajuda. Essas são privações da própria essência da saúde.

Essa equivalência da essência da saúde com a essência do Dasein não é al go que possa ser visto pelo leigo, tampouco diagnosticado pelo médico, porque é um pressuposto ontológico. M as as potencialidades saudáveis mostram-se a cada dia em nosso comportamento e podem ser compreendidas por qualquer um, em sentido pré-ontológico, tanto em relação a si mesmo quanto em relação aos que convivem conosco. Sabemos quando estamos bem de saúde ou quando nosso filho está bem. Dequemaneira isto acontece? $N$ ão pelo uso de um meio de diagnóstico qualquer, mas apenas porque temos a compreensão de nossas próprias potencialidades de ser, preocupamonos conosco; no entanto, o ser-com-os-outros que nós somos dá-se como preocupação ou solicitude(Fürsorge), o quesignificaqueestamosatentos ao modo como se comportam e compreendemos quando o seu comportamento revela uma falta, uma carência de potencialidade.

M as essa indicação de características ônticas já adianta muito a analítica existencial da saúde de tal modo a passar por cima de seus modos ontológicos. Em Ser e tempo ${ }^{7}$, H eidegger diz que os modos fundamentais da potencialidade de ser dependem de o Dasein ganhar-se a si mesmo, escolher a si, projetando-se em sua potencialidade de ser mais própria (a propriedade) ou per- der-se, entregando-se ao que ele não é, isto é, a mundanidade mediana (a impropriedade). I sso exige que se examine a pertinência da saúde à existencialidade nos modos da impropriedade e da propriedade.

\section{Expandindo e concluindo}

Qual a relação entre saúde existencialidade, entendida esta como a trama da estrutura ontológica do Dasein? Defendo aqui o posicionamento de que saúde não é um constituinte específico dessa estrutura, isto é, não é um existencial. A analítica existencial da saúde étributária de uma articulação bem pensada dos constituintes da estrutura do Dasein tal como exposta em Ser e tempo ${ }^{7}$ e demais obras de $\mathrm{H}$ eidegger ${ }^{1-3,7,8}$. Ao modo existenciário da privação da saúde denomino "padecimento", palavra que destaca a disposição (Befindlichkeit) do Dasein na privação como um estar mal, como sofrimento. Com relação ao plano existenciário, proponho que a saúde e sua privação sejam analisadas nos três modos fundamentais da existencialiade do $\mathrm{Da}$ sein: (1) a essência extática, em seu ser-em (o Da); (2) o modo impróprio de ser; e (3) o modo próprio de ser.

0 que está dito até aqui, quanto ao plano ontológico, é que a essência da saúde identificase com a própria essência extática do Dasein, em sua abertura primordial ao ser. A essência extática é o que abre os modos da potencialidade de ser do Dasein e os mantém abertos no Da do Dasein, ou seja, no seu ser aí, no seu estar lançado ao mundo. Da abertura resultam todas as potencialidades de ser do Dasein no plano existenciário. Essas potencialidades são também possibilidades de escolha, que sefundam na liberdadetranscendente do Dasein.

No modo de ser impróprio, o Dasein não existe de forma singularizada, mas numa condição indiferenciada e repetitiva, que se conforma à medianidade (Durchschnittlichkeit) da mundanidade. Como diz Heidegger, a impropriedade determina o modo de ser do Dasein em tudo o quetem demais concreto: atividades, preferências, interesses e prazeres. $\mathrm{Na}$ cotidianidade mediana, o ser do Dasein, que é o cuidado (Sorge), está desdobrado nos modos da ocupação (Besorge) e da preocupação ou solicitude com os outros (Fürsorge), de acordo com regras e padrões já bem estabelecidos na história e na vida fática. Os modos da ocupação e da preocupação estão prenhes de potencialidades de ser do Da- 
sein: 0 trabalhar com...; o ser hábil para...; o se divertir com...; o ser cuidadoso com...; o zelar por... etc. Estão aí reunidos todos os afazeres, deveres, diversões e relacionamentos que dizem respeito a cada Dasein individual.

É exatamente a constituição ontológica da cotidianidade mediana que, por assim dizer, "modula" a saúde no modo impróprio de ser. M odular significa aqui conferir as determinações formais relevantes para análise das potencialidades saudáveis e de sua privação. Ou seja, a potencialidade de ser, indiferenciada enivelada, que lhe é peculiar, delimita a compreensão do que seja a saúde o o padecimento nesse modo. Não faz parte dessa potencialidade mediana qualquer comportamento que pareça extremado ou exótico. Nada similar a uma exigência de gestas de heroísmo ou de autossacrifícios de santidade. A delimitação ontológica da saúde no modo da impropriedade deve sempre ter em consideração essa base estrutural indiferenciada da cotidianidade que pertence aos modos históricos do $\mathrm{Da}$ sein, sobretudo nas sociedades contemporâneas.

O que é, então, a saúde na manifestação ôntica do modo impróprio? Pode-se dizer que a saúde no modo impróprio é o tranquilo estarem-casa do Dasein, com seu desdobrar-se na ocupação e na coexistência da cotidianidade. É um projetar-se à vontade ou animadamente em todas as potencialidades de ser que já Ihe estão abertas regularmente a cada dia ou que ele mesmo se dá com alguma inventividade. $M$ as isto não quer dizer que a saúde, nesse modo de ser, seja equivalente a um completo bem-estar. A cotidianidade é sempre vivida de acordo com contínuas demandas do mundo que são apresentadas ao Dasein e o sobrecarregam, na medida em queele, como ser aberto, compreen dea natureza dessas solicitações e devefornecer respostas. Vem à tona aqui o fenômeno do estresse (Belastung) que, segundo diz $\mathrm{H}_{\text {eidegger }}{ }^{1}$, éinerente ao exercício da essência extática do Dasein. Ao estresse pertencem inúmeros tipos de "sobrecargas": perturbações, sofrimentos e achaques, que somos obrigados a suportar e para os quais temos de dar algum tipo de resposta para seguir adiante na cotidianidade. 0 estresse vem do carregar 0 fardo (Last), um existencial referido em Ser etem$\mathrm{po}^{7}$. A existência serevela como fardo que tem de ser carregado. 0 estresse, como manifestação ôntica do fardo, está conectado com nossa liberdade de ser; é ele que torna a vida mais intensa e digna deser vivida. Por queisto acontece? H eidegger ${ }^{3}$ responde, placidamente, "não se sabe" (Das Sein ist als Last offenbar geworden. Warum, weiß man nicht - A existência está manifesta como peso. Por quê? Não se sabe).

É por referência à condição existencial da cotidianidade que a privação da potencialidade de ser do Dasein deve ser analisada ontologicamente como privação do ser-sadio e onticamente como padecimento. No padecimento, o homem compara-se consigo mesmo e com os outros em sua potencialidade de ser. Suas potencialidades de ser mostram-se mais rígidas ou restritas no sentido deserem capazes de responder às exigências da ocupação e da convivência cotidianas e inclusive para responder às demandas que se expressam como estresse. As restrições a sua liberdade tomam os modos da impotência, comunicados assim: não poso maisfazer...; não posso mais me divertir com...; não mais su porto...; tive de deixar de... Portanto, essas expressões traduzem a privação de alguma potencialidade concreta de ser que é sentida como padecimento. Por exemplo, alguém que sofre de uma paralisia dos membros inferiores não mais pode andar, nadar etc. Essa privação, contudo, não é avaliada pelo que representa de perda para o presente, mas pelo que significa em relação a um projeto de vida, ou seja, tendo em conta um horizonte de temporização. 0 não mais posso quer dizer: aquilo que desejei ser não mais se dará, devo pensar em outra coisa; ou ainda: mantenho meu projeto, mas irei realizá- lo de uma maneira diferente. Contudo, 0 padecimento pode abrir uma potencialidadeinédita de ser em sentido ôntico, o que tem a ver com o desenvolvimento de uma habilidadecompensatória da sua perda de liberdade. Por exemplo: quem tem sua perna amputada aprende a usar uma prótese; quem apresenta paralisia dos membros inferiores aprende a usar uma cadeira de rodas. A habilidade compensatória redefine 0 projeto: por exemplo, se alguém pretendia ser atleta de basquetebol antes de sofrer uma paralisia, tem a opção de integrar uma equipe de jogadores portadores de deficiência.

$M$ as para que possa emergir uma habilidade compensatória, faz-se necessário manter a essência da saúde como fonte de potencial idades de ser. Em condições graves de privação da abertura da essência extática do Dasein, o homem experimenta dificuldade de acesso a potencialidades inéditas. É-Ihe difícil ou impossível desenvolver a habilidade definal idade adaptadora, que contorne ou compense sua deficiência na vida cotidiana.

Por fim, quero tecer breves considerações acerca da saúde no modo de ser da propriedade, um existencial que às vezes se traduz de maneira um pouco tendenciosa como autenticidade. 
Como deve ser entendida a modulação da saúde nesse modo? Por certo, não se deve recorrer à modulação determinada pela via da medianidade cotidiana, na medida em que a propriedade é a determinação do Dasein por si mesmo, quando percorre um caminho de escolhas de singularização existencial eao defrontar-se com seu angustiar-se com sua própria existência.

Nesse caminhar existenciário, o Dasein deve sedecidir por setrazer de volta a si mesmo, emergir de sua submissão à medianidade do impessoal ( $M$ an) e reparar sua falta de escolha. Sua escoIha far-se-á doravante por uma potencialidade deser queéo seu ser si-mesmo em sentido pessoal. Não pretendo repassar todas os constituintes existenciais que balizam o percurso desse caminho (clamor da consciência, débito, projeto, visão, decisão etc.). 0 que é importante aqui é ter claro que a modulação da saúde e, portanto, do padecimento não pode ser feita, por assim dizer, em maneira heterônoma. A fonte dessa modulação é sempre o ser próprio pessoal do Dasein, como escolha de sua escolha. Portanto, o Dasein não mais precisa pautar sua potencial idade de ser pelas normas e padrões da medianidade cotidiana. Isto significa que o modo próprio traz a si a legítima determinação da saúde como abertura a todas as potencialidades próprias de ser. Por outras palavras, o modo de ser próprio é saudável por si mesmo, erguendo-se como padrão de saú- de acima de qualquer constituinte da mundanidade e dos juízos que daí possam advir. M esmo que o $D$ asein possa se reconhecer em padecimento, sua eventual compreensão nessa privação (como um não posso, não consigo ou não me é mais possível) não tem o vigor determinante que está presenteno modo impróprio, deacordo com a modulação da medianidade cotidiana. É que seu ser está resoluto noutro projeto de abertura, como abertura para si. M ais ainda: pode ser que a privação da saúde, o padecimento, forneça a ocasião para quese abra a potencialidade do modo próprio. É o que se pode denominar de reatamento do Dasein em seu ser-no-mundo.

0 reatamento é o encontro do Dasein com sua potencialidade de ser própria, que se forma como projeto antevisto no modo do padecimento e no angustiar-se verdadeiro com sua própria existência, na perspectiva segura da possibilidade da morte. 0 Dasein leva-se a si mesmo ao momento da decisão e se refaz em sua totalidade existencial. Como Dasein que sou reato-me comigo e reato-me com o mundo, num só projeto quanto a minha potencialidade mais própria. Significa que me ato por inteiro e livre em minhas potencialidades de ser, e não mais pautado pela mundanidade impessoal. N esta condição existencial, pode-se dizer que há saúde e saúde por inteiro, mesmo que o Dasein ainda se compreenda estando em padecimento.

\section{Referências}

1. Heidegger M. Zollikon Seminars: protocols - conversations - letters. Chicago: Northwestern University Press; 2001.

2. Heidegger M. Seminários de Zollikon (editado por Medard Boss). Petrópolis: Vozes; 2001.

3. Heidegger $M$. Sein und Zeit. Tübingen: Max Niemeyer Verlag; 1967.

4. Loparic Z. Binswanger, leitor de Heiddeger: um equívoco produtivo? Natureza Humana 2002; 4(2):383-413.

5. Heidegger M. The essence of truth, on Plato's cave allegory and Theaetetus. New York, London: Continuum; 2002.

6. Heidegger $\mathrm{M}$. The fundamental concepts of metaphysics world, finitude, solitude. Bloomington: Indiana University Press; 2001.
7. Heidegger M. Ser e tempo. v. 2. Petrópolis: Vozes; 1989.

8. Heidegger M. Nietzsche. v. 1. San Francisco: HarperSanFrancisco; 1991.

9. Canguilhem G. O normal e o patológico. Rio de Janeiro: Forense; 1978.

10. Heidegger $M$. The essence of freedom, an introduction to philosophy. New York, London: Continuum; 2005.

Artigo apresentado em 16/08/2007

Aprovado em 04/12/2007

Versão final apresentada em 04/01/2008 